\title{
Comparative Evaluation of Smear Layer Removal Using Four Different Irrigation Techniques: An in-vitro Study
}

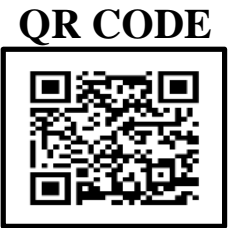

\section{AJAY CHHABRA ${ }^{1}$, APOORVA RANA², NISHA GARG $^{* 3}$, RUHANI BHATIA ${ }^{4}$, SHOBIT SETHI ${ }^{5}$}

INTRODUCTION: Irrigation is the vital part of root canal debridement. Usually post biomechanical preparation, the canal walls are covered by smear layer. It is important to remove this layer before obturation for better bond between the filling and walls. Conventional needle irrigation doesn't give us adequate cleaning, therefore, new irrigation techniques are being tried to facilitate better smear layer removal.

AIM: The aim was to evaluate and compare the smear layer removal by PATS, EndoActivator device, Passive ultrasonic irrigation and side vent needle irrigation from canal walls.

MATERIALS AND METHODS: 60 extracted mandibular premolars were instrumented up to 35/.04 with Heroshaper files. Samples were divided into 4 groups randomly before final irrigation as follows: Group I $(n=15)$ : Irrigation with side vent needles (Nexus ltd.,India), Group II ( $\mathrm{n}=15$ ): Irrigation with EndoActivator (Advanced Endodontics, Santa Barbara, CA ) Group III ( $\mathrm{n}=15$ ): Irrigation with PATS ( InnovationsEndo,India), Group IV ( $\mathrm{n}=15$ ): Irrigation with ultrasonic tips (Mani inc.). Teeth were split and one-half of each tooth was chosen for SEM examination. The images were taken at apical third and scoring was done according to criteria by Torabinejad et al in 2003. Data obtained were analyzed using Kruskal-Wallis analysis of variance followed by MannWhitney U-test for individual comparison.

RESULTS: All irrigating systems remove smear layer but PUI has better cleaning ability as compared to other groups. CONCLUSION: Passive ultrasonic irrigation shows better smear layer removal as compared to other techniques.

KEYWORDS: Smear Layer, Irrigation, EndoActivator, PATS, EDTA, Side Vent Needle

\section{INTRODUCTION}

The success of endodontic therapy is mainly dependent on thorough chemo-mechanical preparation of the root canal system. Biomechanical preparation of root canal leads to formation of smear layer. This layer comprises both organic and inorganic substances as well as odontoblastic process fragments, other necrotic material, some microorganisms and byproducts. This layer results in prevention of penetration of intracanal medicaments in the dentinal tubules and has a detrimental effect on the sealing ability of obturating material three dimensionally. Therefore, it is imperative to remove the smear layer. ${ }^{1}$ Irrigation is responsible for killing organisms, flushing out the debris and removing the smear layer from prepared canals. Also, it has been reported that some of the canal parts remain un-instrumented during canal preparation. ${ }^{2}$ Therefore, for complete disinfection of the root canal system it is important that an irrigant is in direct contact with the entire canal walls. ${ }^{3}$
The most commonly used irrigation technique is the conventional needle irrigation. It involves replenishing and exchange of the irrigant in the apical third of the canal. The effectiveness of this technique is determined by the depth that the needle penetrates. The irrigant exchange doesn't occur beyond 1-1.5 mm of needle tip. The irrigant beyond that remains stagnant leading to insufficient cleaning of canals. ${ }^{2}$

Since the efficiency of this irrigating technique is not very superior, an improvement in techniques is required to achieve better cleaning especially in complex areas. Various new techniques have developed over the time ranging from manual dynamic agitation of gutta percha cones to ultrasonically activated irrigation. ${ }^{4}$ One such system that has developed for an efficient cleaning is the EndoActivator system (Advanced Endodontics, Santa Barbara, CA) which is sonically activated irrigation system produces fluid agitation vigorously in the 
canals. ${ }^{5}$ Another technique is Passive ultrasonic irrigation (PUI) which uses a non contacting and non cutting file that is activated ultrasonically. ${ }^{3}$

Recently, a new irrigating system Pro-Agitator Tip System (PATS) (InnovationsEndo Ltd, Nasik, Maharashtra, India) has been launched in 2017, that contains a handpiece with an autoclavable polymer tip that agitates the irrigant ultrasonically.

The aim of this in vitro study was to compare the efficacy of PATS, the EndoActivator device, Passive ultrasonic irrigation and side vent needle irrigation in the removal of organic debris and smear layer from root canal walls.

\section{MATERIALS AND METHODS}

The study was done in the Department of Conservative Dentistry and Endodontics, Bhojia Dental College and Hospital, Bhud, Baddi (H.P). Sixty freshly extracted mandibular premolars which had caries, or were extracted for orthodontic and periodontal reasons and had single root canals with mature apex. External surfaces of teeth were debrided with an ultrasonic scaler (Woodpecker) and kept in normal saline (Aishwarya Lifesciences), until used.

A diamond disc was used to decoronate the samples so as to have a consistent working length of $15 \mathrm{~mm}$. \#15 Kfile was used to negotiate the canal, until it passed the apex. Working length was assessed $1 \mathrm{~mm}$ short of the length, when file tip was visible at the apex.

The samples were instrumented in crown- down technique using Heroshaper (Micromega co. ltd.) files 20/.04,25/.04,30/.04 keeping the master apical file 35/.04. During instrumentation, files were coated with Prep Canal (Ammdent, India) for lubrication and irrigated with $1 \mathrm{ml}$ of $3 \%$ sodium hypochlorite solution (Dentpro, Amrit chemicals ltd, Punjab, India) . After completion of instrumentation, apices were blocked using wax.

Samples were divided into 4 groups randomly before final irrigation as follows:

Group I (n=15): Irrigation with side vent needles (Nexus ltd., India): $10 \mathrm{ml}$ of $3 \% \mathrm{NaOCl}$ was delivered over a time period of 90 seconds, followed by $3 \mathrm{ml}$ of $17 \%$ EDTA for 2 minutes and final rinse with $2 \mathrm{ml}$ normal saline for 1 minute.

Group II (n=15): Irrigation with EndoActivator (Advanced Endodontics, Santa Barbara, CA ): Activated for 30 seconds until $10 \mathrm{ml} 3 \% \mathrm{NaOCl}$ was used, total activation time was 90 secs, followed by 3 $\mathrm{ml}$ of $17 \%$ EDTA which was activated for 60 secs and total contact time of EDTA was 2 minutes and final rinse was done with $2 \mathrm{ml}$ of normal saline which was activated for 1 minute.

Group III $(\mathbf{n}=\mathbf{1 5})$ : Irrigation with PATS (InnovationsEndo, India): $10 \mathrm{ml}$ of warm $3 \% \mathrm{NaOCl}$ was delivered over a time period of 90 seconds, followed by $3 \mathrm{ml}$ of $17 \%$ EDTA over a duration of $1 \mathrm{~min}$ and was allowed to remain for 2 mins followed by final rinse with $2 \mathrm{ml}$ normal saline for 1 minute.

Group IV ( $\mathbf{n = 1 5}$ ): Irrigation with ultrasonic tips (Mani inc.): Activation cycle of 30 seconds until $10 \mathrm{ml} \mathrm{3 \%}$ $\mathrm{NaOCl}$ was used, which was activated for 90 secs, followed by $3 \mathrm{ml}$ of $17 \%$ EDTA activated for 60 secs and the total contact time of EDTA was 2 minutes followed by final rinse with $2 \mathrm{ml}$ of normal saline which was activated for 1 minute.

Paper points were used to dry the canals, and orifices were blocked with cotton pellets. Deep grooves were made on buccal as well as lingual surfaces of root with diamond discs. Teeth were split using chisel and mallets. One-half of each tooth was chosen for SEM examination to evaluate smear layer removal.

The images were taken at apical third and scoring was done according to criteria by Torabinejad et al. in 2003: (i) $0=$ No smear layer, (ii) 1 = Moderate smear layer, (iii) $\mathbf{2}=$ Heavy smear layer .The results were tabulated and analyzed statistically.

\section{RESULTS}

The results of the in-vitro study show a significant difference in the smear layer removal by different irrigation systems used. The table 1 shows a significant difference in removal of smear layer between group IV and group I and group II. Group IV shows better smear layer removal as compared to other groups. Whereas, no significant difference was seen between group II and group III, stating that the amount of smear layer removal by both these techniques is similar as seen in figures 1-4. 


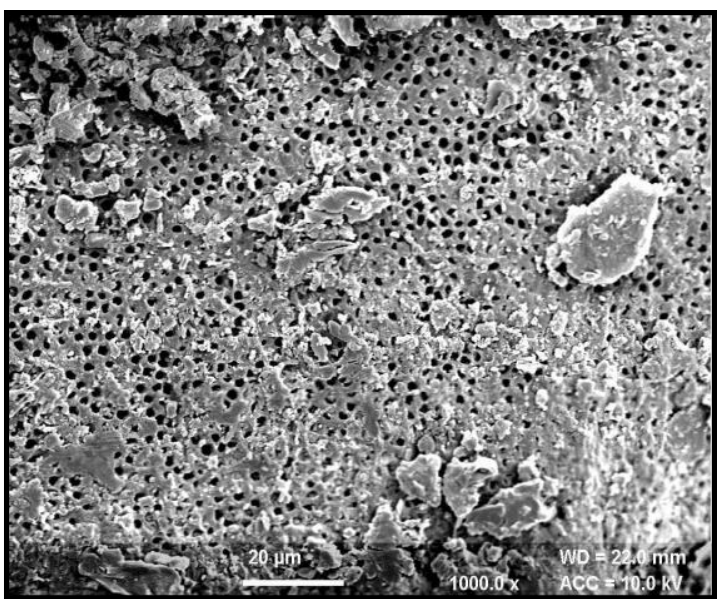

Figure 1. Smear layer removal in the apical third using EndoActivator

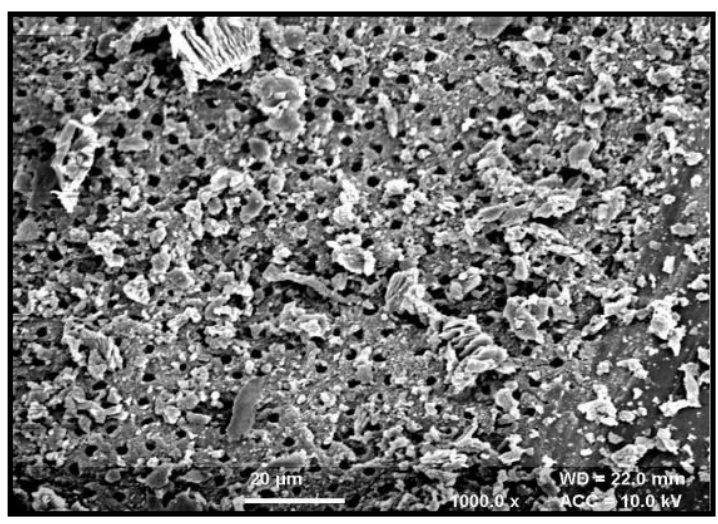

Figure 2. Smear layer removal in the apical third using PATS

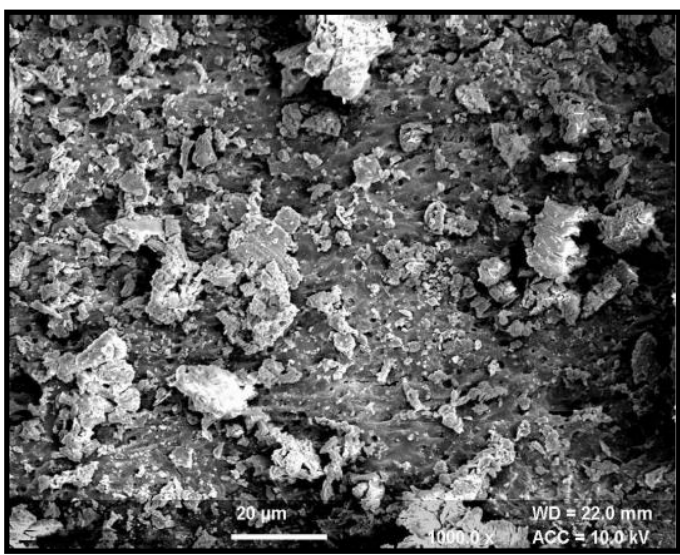

Figure 3. Smear layer removal in the apical third using Side Vent Needle

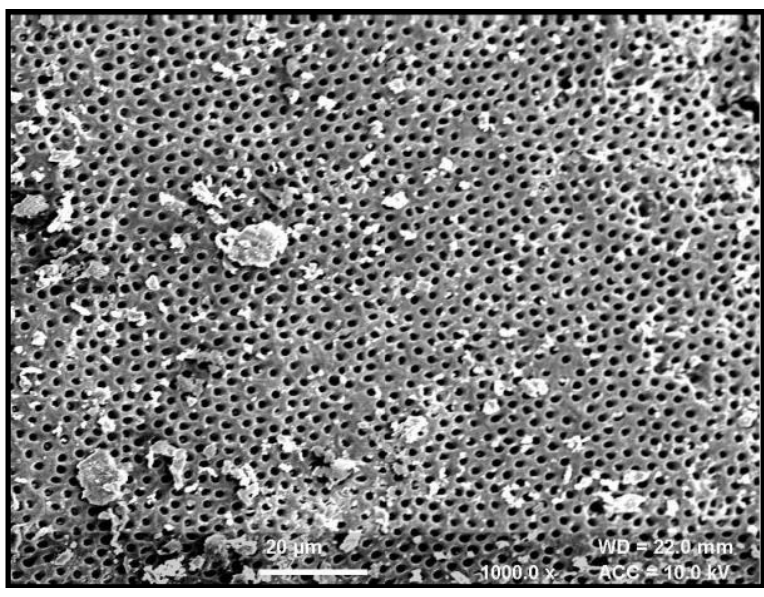

Figure 4. Smear layer removal in the apical third using Passive Ultrasonic Irrigation

\section{DISCUSSION}

Root canal system debridement is important for endodontic success. Biomechanical preparation techniques forms a layer constituting both organic as well as inorganic particles which is called smear layer. Irrigation leads to better cleaning than that which is achieved preparing root canal alone. It kills microorganisms, flushes debris, and removes the smear layer. Failure in removing smear layer during final irrigation can have a negative effect on the prognosis of treatment. ${ }^{6}$

Different irrigants are used to flush out the debris, tissue that has been necrosed, bacteria as well as the smear layer formed by the biomechanical preparation of the root canals. Irrigating solutions that dissolve organic and inorganic material to eliminate the microbes and increase chances of sealing filling material three dimensionally are used to remove the layer. Sodium hypochlorite $(\mathrm{NaOCl})$ has been used most commonly as an irrigating solution in endodontics since $1920 \mathrm{~s}$. $\mathrm{NaOCl}$, is a deproteinizing agent, and EDTA, is a calcium-chelating agent, which when used alternately lead to effective smear layer removal. ${ }^{3}$ Irrigants when in contact with root canals show improved cleanliness. The conventional needle irrigation technique delivers the irrigant not more than o-1.1 mm beyond needle tip. This doesn't give us sufficient cleaning of the complex anatomical areas (eg. lateral canals, isthmuses, fins, and accessory canals). ${ }^{7} \mathrm{~A}$ vapor lock causes trapping of air in the root canal especially apical part, thus hindering the irrigant exchange and also has an effect on the efficacy of debridement. New devices are being used that increase 


\begin{tabular}{|c|c|c|}
\hline $\begin{array}{c}\text { APICAL } \\
\text { THIRD }\end{array}$ & MEAN & $\begin{array}{c}\text { STANDARD } \\
\text { DEVIATION }\end{array}$ \\
\hline $\begin{array}{c}\text { GROUP II } \\
\text { (EN) }\end{array}$ & 2.33 & 0.488 \\
\hline $\begin{array}{c}\text { GROUP III } \\
\text { (PATS) }\end{array}$ & 2.40 & 0.507 \\
\hline $\begin{array}{c}\text { GROUP IV } \\
\text { (PUI) }\end{array}$ & 1.20 & 0.414 \\
\hline
\end{tabular}

Table 1. Mean and standard deviation scores values of smear layer removal at apical third using different irrigation techniques.

(a. IN_VITRO score is constant when Group = SVN. it has been omitted.)

Conventional irrigation with syringes is still used by both general practitioners and endodontists. It involves delivering the irrigant into the canal with needles of different gauges, passively or with agitation. Agitation is done by the up and down motion of needle in the canal. Some needles are designed in such a way that the irrigant is delivered through the distal most end whereas others deliver irrigant in a lateral manner through closed ended side vent way. Syringe irrigation combined with different activation methods are mainly used as final irrigation after completion of biomechanical preparation. ${ }^{3}$

Ultrasound usage during root canal therapy for irrigation is advantageous for endodontic disinfection. The range of frequencies used is between 25 and 40 $\mathrm{kHz}$. The efficacy in irrigation is due to two properties: "cavitation" and "acoustic streaming". The effect of cavitation is limited and minimal, only at the tip of the instrument being used, whereas acoustic streaming has a more significant effect. Bubbles of positive and negative pressure are created by the ultrasound in the liquid that they contact, which become unstable and collapse leading to an implosion resembling that of vacuum decompression. The detergent effect of ultrasonics is due to the explosion and implosion that releases impact energy. It involves the use of a needle activated by ultrasound. In this way, the irrigant is released into the canal and it is also activated by the action of ultrasonic needle at the same time. ${ }^{3}$

The EndoActivator System (Dentsply Tulsa Dental Specialties, Tulsa, OK) is a sonically-driven canal irrigation system comprising a handpiece which is portable and 3 polymer tips which are flexible and disposable and have different sizes, which don't cut into dentin. This design permits for safe activation of the flow and distribution of irrigants within the root canals, especially in the apical third region. ${ }^{8}$

different irrigants in canals and produce vigorous intracanal agitation of those irrigants. This system has been shown to clean the simulated lateral canals at 4.5 and $2 \mathrm{~mm}$ from working length much better as compared with traditional needle irrigation alone, and it reportedly removed the smear layer when used with demineralising agents like EDTA and dissociated clumps of biofilm from the curved canals of molars. ${ }^{5}$

This study was done to evaluate the effectiveness of different irrigation techniques in removing the smear layer . The four different techniques used are: side vent needles, Endoactivator, U-files and PATS (Pro Agitator Tip System). In the present study, the maximum smear layer removal in the apical third was achieved with the U-files followed by PATS, Endoactivator and Side vent needles.

The concept of using ultrasonic devices in endodontics was first introduced by Richman in 1957. Passive ultrasonic irrigation was first described by Weller et al in 1980. In the present study, PUI has been used as one of the methods of irrigant agitation. A small size 15 file is inserted in the centre of the canal as far as the apical third, once the root canal is prepared till the master apical file. It is then filled with an irrigant that is activated by an ultrasonically oscillating file. The active streaming of the irrigant is responsible for contacting a greater surface area of the canal wall thus enhancing its cleaning action. Thus, higher velocity and irrigant flow volume in canals can be a possible explanation as to why PUI has improved cleaning action. ${ }^{9}$

In the current study, scanning electron microscope has been used to study the smear layer removal. Boyde, Switsur and Stewart (1963) appear to be among the first to describe the type of surface deposits in greater detail using the Scanning electron microscope. Since then SEM has been one of the most efficient methods of evaluation of smear layer. ${ }^{10}$

In this study, the use of Passive Ultrasonic irrigation was demonstrated to be the better mode of agitation. Following Passive ultrasonic agitation, a better removal of smear layer was noticed, which subsequently revealed the least smear layer scores in the SEM micrographs. The smear layer scores show a highly statistically significant difference when 
compared to conventional syringe irrigation $(\mathrm{p}<$ 0.005).

Sabins et al. ${ }^{11}$ and Capar et al. ${ }^{12}$ reported that passive ultrasonic irrigation is superior in removing smear layer and debris from canals as opposed to passive sonic irrigation.

The combination of ultrasonics and EDTA has been previously recorded in literature. Kuah et al demonstrated the efficacy of $17 \%$ EDTA in smear layer removal, with and without ultrasonics, in vitro. One hundred and five extracted premolars were randomly divided into seven groups and were then instrumented with different final irrigating protocols. Specimens were studied using scanning electron microscope and scoring was done for smear layer and debris removal. groups with EDTA and ultrasonic irrigation showed significantly cleaner canals and it was therefore concluded that EDTA when combined with ultrasonics and then applied for 1 minute showed more efficient smear layer and debris removal in the apical third of canals. ${ }^{13}$

The present study shows huge amounts of smear layer in the apical third when irrigated with side vent needles as compared to other systems. This can be because the cleaning of syringe is inadequate as compared to other methods and is dependent on the root canal anatomy, the depth of placement and the diameter of the needle. It has been shown that irrigants can only progress $1 \mathrm{~mm}$ beyond the tip of the needle. This result is in accordance with that of Karade et al. which showed similar results. ${ }^{14}$

Akveld NAE in 2007 when compared passive ultrasonic irrigation it was seen that PUI performed better than that of Endoactivator. ${ }^{15} \mathrm{Li}$. D conducted a study which compared four irrigation techniques in removing calcium hydroxide \& it was seen that greater amount of calcium hydroxide was removed using PIPS and ultrasonic at apical area when it was compared with EndoActivator and needle irrigation. ${ }^{16}$ This result is in accordance with our study.

Similarly, Khaord et al. ${ }^{17}$ and Mozo et al. ${ }^{18}$ also concluded that PUI has higher efficacy in pulp tissue and dentinal debris removal as compared to conventional needle irrigation techniques. This can be attributed to high speed and more flow volume of the irrigating solution when activated ultrasonically, therefore, eliminating more debris.

While in other study carried out by Khalap et al. ${ }^{19}$ it was concluded that sonic activation is better than ultrasonic activation in debris removal. The reason given was that PUI creates acoustic microstreaming producing enough shear stresses that disrupts debris from prepared canals. Undesirable dampening effect of the amplitude of its characteristic nodes and antinodes pattern was created, especially on contact of the instrument with the lateral walls of canal. But in sonic system, no influence by lateral wall contact is seen. ${ }^{19}$

In this study, it was seen that EndoActivator has more efficacy in removing smear layer than syringe irrigation. On the contrary a study done by UrozTorres et al. ${ }^{20}$ showed that there was no difference between Endoactivator and syringe irrigation in smear layer removal. This variation of result might be due to difference in the methodology.

Rödig et al. ${ }^{21}$ in his study concluded that there was no difference between smear layer removal by EndoActivator, PUI and non-activated group at apical third. Variation in the result can be due to the variable methodology.

\section{CONCLUSION}

Although instrumentation removes most of the canal debris and smear layer from root canal area irrigation plays an important role in flushing out of debris and removing smear layer from complex anatomical areas of the canal that remain inaccessible to our instruments.

Within the limitations of the present in-vitro study results revealed that none of the tested irrigation devices were able to completely remove smear layer from the canal. However, passive ultrasonic irrigation removed more smear layer in the apical third of root canal as compared to other devices and this difference was statistically significant. Moreover, PATS and EndoActivator performed better than side vent needles in removing smear layer which was also statistically significant.

\section{REFERENCES}

1. El-Din Saber S, Hashem AAR. Efficacy of Different Final Irrigation Activation Techniques on Smear Layer Removal. J Endod 2011; 37:1272-5. 
2. Gade VJ, Sedani SK, Lokade JS, Belsare LD, Gade JR. Comparative evaluation of debris removal from root canal wall by using EndoVac and conventional needle irrigation: An in vitro study. Contemp Clin Dent 2013; 4:432-6.

3.Gu LS, Kim JR, Ling J, Choi KK, Pashley DH, Tay FR. Review of contemporary irrigant agitation techniques and devices. J Endod 2009; 35:791-804.

4.R. Castagnola et al. Efficacy of three different irrigation techniques in the removal of smear layer and organic debris from root canal wall: a scanning electron microscope study. Giornale Italiano di Endodonzia 2014; 28:79-86.

5. Kumar $\mathrm{V}$ et al. Comparison of efficacy of various root canal irrigation systems in removal of smear layer generated at apical third: An SEM study. J Conserv Dent. 2015; 18(3):252-6.

6. Ahmetoglu F, Keles A, Yalcin M, Simsek N. Effectiveness of different irrigation systems on smear layer removal: A scanning electron microscopic study. Eur J Dent. 2014;8(1):53-7.

7. Birajdar A, Sathe S, Dixit M, Shanmugasundaram S. Comparative evaluation of the efficacy of three different irrigation devices in removal of debris from isthmus: An in vitro study. Endodontology 2016;28:26.

8. Mancini M, Cerroni L, Iorio L, Armellin E, Conte G, Cianconi L. Smear layer removal and canal cleanliness using different irrigation systems (EndoActivator, EndoVac, and passive ultrasonic irrigation): field emission scanning electron microscopic evaluation in an in vitro study. J Endod. 2013;39(11):1456-6o.

9. van der Sluis LW, Versluis M, Wu MK, Wesselink PR. Passive ultrasonic irrigation: a review of the literature. International Endodontic Journal 2007; 40:415-26.

10. Narmatha VJ, Thakur S. Evaluation of manual dynamic activation, passive ultrasonic irrigation and canalbrush on smear layer removal - a scanning electron microscopic study. International Journal of Advanced Research 2015; 3:390-400.

11. Sabins RA, Johnson JD, Hellstein JW. A comparison of the cleaning efficacy of short-term sonic and ultrasonic passive irrigation after hand instrumentation in molar root canals. J Endod. 2003;29(10):674-8.

12. Çapar ID, Ari Aydinbelge H. Effectiveness of various irrigation activation protocols and the self-adjusting file system on smear layer and debris removal. Scanning. 2014;36(6):640-7.

13. Kuah HG et al. The effect of EDTA with and without ultrasonics on removal of the smear layer. J Endod. 2009;35(3):393-6.
14. Karade P, Chopade R, Patil S, Hoshing U, Rao M, Rane N, Chopade A, Kulkarni A. Efficiency of Different Endodontic Irrigation and Activation Systems in Removal of the Smear Layer: A Scanning Electron Microscopy Study. Iran Endod J. 2017;12(4):414-8.

15. Akveld NAE, Hiep STP. The efficacy of sonic irrigation (EndoActivator) and type of irrigant on removing artificially placed dentine debris from the apical root canal, Academic Centre for Dentistry Amsterdam (Amsterdam, the Netherlands) in association with Department of Endodontology of University of La Sapienza (Rome, Italy), 2007.

16. Li D, Jiang S, Yin X, Chang JW, Ke J, Zhang C. Efficacy of Needle, Ultrasonic, and Endoactivator Irrigation and Photon-Induced Photoacoustic Streaming in Removing Calcium Hydroxide from the Main Canal and Isthmus: An In Vitro Micro-Computed Tomography and Scanning Electron Microscopy Study. Photomed Laser Surg. 2015 Jun;33(6):330-7.

17. Khaord P, Amin A, Shah MB, Uthappa R, Raj N, Kachalia T, et al. Effectiveness of different irrigation techniques on smear layer removal in apical thirds of mesial root canals of permanent mandibular first molar: A scanning electron microscopic study. J Conserv Dent 2015;18:321-6.

18. Mozo S, Llena C, Forner L. Review of ultrasonic irrigation in endodontics: Increasing action of irrigating solutions. Med Oral Patol Oral Cir Bucal 2012;17:e512-6.

19. Khalap ND, Kokate S, Hegde V. Ultrasonic versus sonic activation of the final irrigant in root canals instrumented with rotary/reciprocating files: An invitro scanning electron microscopy analysis. J Conserv Dent. 2016 Jul-Aug;19(4):368-72.

20. David Uroz-Torres, Maria Paloma Gonza'lezRodrı'guez and Carmen Maria Ferrer-Luque. Effectiveness of the EndoActivator System in Removing the Smear Layer after Root Canal Instrumentation. J Endod 2010; 36:308-311.

21. Rödig T, Döllmann S, Konietschke F, Drebenstedt $S$, Hülsmann M. Effectiveness of different irrigant agitation techniques on debris and smear layer removal in curved root canals: A scanning electron microscopy study. J Endod 2010; 36(12): 1983-7. 
Source of support: Nil, Conflict of interest: None declared

Cite this article as:

Chhabra A, Rana A, Garg N, Bhatia R, Sethi S. Comparative evaluation of smear layer removal using four different irrigation techniques: an in- vitro study. Int Healthc Res J. 2019;3(2):82-86. doi: 10.26440/IHRJ/0302.05.521082

\section{AUTHOR AFFILIATIONS:}

1. Former Professor \& Principal

2. Post Graduate Student

3. Professor \& Head (Corresponding Author)

4. Senior Lecturer

Department of Conservative Dentistry and Endodontics, Bhojia Dental College and Hospital, Bhud, Baddi (Himachal Pradesh)

5. Consultant Orthodontist, Pooran Dental and Cosmetic Clinic, Chandigarh

For article enquiry/author contact details, e-mail at: manuscriptenquiry.ihrj@gmail.com 